\title{
A Bacillus subtilis Mutant Requiring Dipicolinic Acid for the Development of Heat-resistant Spores
}

\author{
By G. BALASSA, * P. MILHAUD AND E. RAULET \\ Unité de Microbiologie, C.N.R.S., Montpellier, France \\ M. T. SILVA† AND J. C. F. SOUSA \\ Centre of Experimental Cytology, University of Porto, Porto, Portugal
}

(Received 20 June 1978; revised 26 July 1978)

\begin{abstract}
A Bacillus subtilis mutant is described which forms heat-resistant spores only in the presence of external dipicolinic acid (DPA). The mutation, $d p a-1$, is localized in a new sporulation locus, linked to $p y r A$. The $d p a-1$ strain is unable to synthesize DPA but can incorporate external DPA. The amount of DPA incorporated, the frequency of heat-resistant spores and their degree of resistance are all dependent on the concentration of external DPA. Spores of $d p a-l$ strains exhibit normal resistance to most chemicals, including octanol and chloroform, but not to ethanol, pyridine, phenol and trichloroacetic acid. Complete resistance to the latter group depends on DPA. DPA incorporation is slow and apparently requires an energy supply but not protein synthesis. Direct involvement of DPA in the heat-resistance of the spores is suggested. Thin sections of DPA-less spores exhibit clearly visible cytoplasmic membranes and ribosomes. These structures are absent or less visible in the core of spores obtained with added DPA.
\end{abstract}

\section{INTRODUCTION}

Although bacterial spores are well known for their resistance to heat, desiccation and various chemical agents, the mechanism of such resistance is not well understood. Dipicolinic acid (DPA) has been thought to play an important role in heat resistance. Such a belief was mainly based on indirect arguments, reviewed by Gould \& Dring (1974): DPA is present in all bacterial endospores, its synthesis closely precedes the appearance of heat resistance, and in several systems there is a quantitative correlation betwen DPA content and heat resistance. This view was, however, challenged by brief (and still unconfirmed) reports of mutants which form DPA-less but heat-resistant spores (Hanson et al., 1972; Zytkovicz \& Halvorson, 1972). Such results were inconsistent with those obtained with other mutants unable to synthesize DPA, the spores of which remained heat-sensitive unless external DPA was added (Sebald, 1968; Fukuda \& Gilvarg, 1968). Clearly, detailed investigation of further DPA-less mutants is required.

A Bacillus subtilis mutant with spores resistant to chloroform but not to heat treatment has been described previously (Balassa \& Yamamoto, 1970). In this paper we report that the heat resistance of spores of this mutant depends directly on the incorporation of added DPA. Our observations confirm the role of DPA in heat resistance and suggest a reconsideration of theories on the mechanism of spore resistance.

* Present address: 10 Impasse Pierre Rouge, 34000 Montpellier, France.

$\dagger$ Present address: 1021 Rua do Campo Alegre, Porto, Portugal. 
Table 1. Strains of Bacillus subtilis used

\begin{tabular}{lcc} 
Strain* & IPCC $\dagger$ no. & \multicolumn{1}{c}{ Genotype } \\
CB22 & 7626 & dpa-1 leu-8 metB5 thr -5 \\
AB12 & 7635 & dpa-I pheA1 trpC2 \\
AC28 & 7697 & dpa-1 trpC2 \\
168 & 7645 & dpa trpC2 \\
PM9 & 7647 & dpa metC3 pheAl trpC2 \\
PM12 & - & dpa metC3 pheAl pyrA1
\end{tabular}

* Strain CB22 was obtained by $N$-methyl- $N{ }^{\prime}$-nitro- $N$-nitrosoguanidine-induced mutagenesis (Balassa, 1969). Strains $A B 12$ and $A C 28$ were obtained by transformation with $C B 22$ and $A B 12$, respectively, as donors. Strains 168, PM9 and PM12 are Spo ${ }^{+}$dpa $^{+}$control strains described by Milhaud et al. (1978).

+ Institut Pasteur Culture Collection.

\section{METHODS}

Strains. The strains used are listed in Table 1. Strains AB12 and PM9 are isogenic except for the markers indicated (it was found, however, that $\mathrm{AB} 12$ had lost its motility and was not transducible). The strains were maintained either at $4{ }^{\circ} \mathrm{C}$ on DN agar tubes or at $-20{ }^{\circ} \mathrm{C}$ on DN agar tubes containing $15 \%$ (v/v) glycerol (Balassa, 1969).

Media and culture conditions. Unless otherwise indicated, sporulating cultures were obtained by inoculating bacteria from a preculture into a nutrient broth sporulation medium at $37^{\circ} \mathrm{C}$ (Schaeffer et al., 1965; Balassa, 1969; Dod et al., 1978). Growth was followed by measuring the absorbance at $550 \mathrm{~nm}$. Time $t_{0}$ was defined as the end of exponential growth; $t_{1}, t_{2}$ etc. indicate sporulation times in hours after $t_{0}$.

Spore resistances. These were measured according to Milhaud \& Balassa (1973). Undiluted samples of sporulating cultures (containing about $5 \times 10^{8} \mathrm{cells} \mathrm{m}^{-1}$ ) were treated for $10 \mathrm{~min}$ at room temperature with $0 \cdot 1 \mathrm{vol}$. toluene, benzene, octanol, chloroform, butanol, $90 \%(\mathrm{v} / \mathrm{v})$ ethanol or $90 \%(\mathrm{v} / \mathrm{v})$ pyridine, or at $4{ }^{\circ} \mathrm{C}$ with $5 \%(\mathrm{w} / \mathrm{v})$ phenol or $5 \%(\mathrm{w} / \mathrm{v})$ trichloroacetic acid (TCA). For heat treatment, unless otherwise indicated, samples were incubated at $80^{\circ} \mathrm{C}$ for $10 \mathrm{~min}$.

Genetic methods. Transformation and transduction experiments were done as described by Milhaud et al. (1978). Dpa- transformants and transductants were obtained by a two step indirect selection method. Colonies were first selected for the loss of an auxotrophic marker. Dpa- colonies were recognized among these colonies by their lighter yellow colour, and their phenotype was confirmed in liquid sporulation cultures.

Electron microscopy. This was done as described by Sousa et al. (1974) without post-staining of the sections.

Dipicolinic acid assay. Samples of sporulating cultures were centrifuged, resuspended in $2 \mathrm{ml}_{2} \mathrm{H}_{2} \mathrm{O}$, autoclaved for $15 \mathrm{~min}$ and centrifuged again. Then $1 \mathrm{ml}$ of supernatant was mixed with $0.25 \mathrm{ml}$ of the reagent described by Janssen et al. (1958). The results were compared with a standard curve of pure DPA (KochLight) assayed in the same conditions.

Protease activity. This was measured on azocasein as described by Dod et al. (1978).

\section{RESULTS}

\section{$D P A$-dependent heat resistance of strain $\mathrm{CB} 22$ spores}

When incubated in a sporulation medium, strain CB22 formed chloroform-resistant $\left(\mathrm{Ch}^{\mathrm{R}}\right)$ spores with high frequency. The number of heat-resistant $\left(\mathrm{T}^{\mathrm{R}}\right)$ spores was much lower, in general well below $1 \%$ (Table 2). The phenotype of the strain with respect to spore resistances is therefore 'chloroform-resistant and heat-sensitive' $\left(\mathrm{Ch}^{\mathrm{R}}, \mathrm{T}^{\mathrm{s}}\right)$. Strain CB22 appears to be an oligosporogenous one (Schaeffer et al., 1965) in which only a small fraction of the cells complete maturation. This fraction varied from one culture to another: it was usually around $10^{-3}$ but in some experiments it reached $10^{-1}$. These variations were probably due to variation between batches of nutrient broth: five independent subclones of CB22 gave similar frequencies of $\mathrm{T}^{\mathrm{R}}$ spores in parallel cultures. There was no genetic heterogeneity in CB22: 10 clones obtained either from $\mathrm{Ch}^{\mathrm{R}} \mathrm{T}^{\mathrm{S}}$ or from $\mathrm{Ch}^{\mathrm{R}} \mathrm{T}^{\mathrm{R}}$ spores all showed the same sporulation frequencies and gave rise to identical strains.

Addition of DPA to the sporulating cultures (Table 2) allowed all the $\mathrm{Ch}^{\mathrm{R}}$ spores to 
Table 2. Heat resistance of $\mathrm{Dpa}^{-}$spores

Cultures of the dpa- 1 strains were allowed to sporulate in the absence of DPA or with DPA added as indicated. After sporulation was completed, the numbers of spores surviving treatment with chloroform $\left(\mathrm{Ch}^{\mathrm{R}}\right)$ and with heat $\left(\mathrm{T}^{\mathrm{R}}\right)$ were measured in each culture.

DPA absent

\begin{tabular}{|c|c|c|c|c|c|c|c|}
\hline \multirow[b]{2}{*}{ Strain } & \multirow{2}{*}{$\begin{array}{l}\text { Time of } \\
\text { heat } \\
\text { treatment }\end{array}$} & \multicolumn{2}{|c|}{ No. of spores $\mathrm{ml}^{-1}$} & \multirow{2}{*}{$\begin{array}{c}\text { Concn } \\
\left(/ / \mathrm{g} \mathrm{ml}^{-1}\right)\end{array}$} & \multirow[b]{2}{*}{ Time* } & \multicolumn{2}{|c|}{ No. of spores $\mathrm{ml}^{-1}$} \\
\hline & & $\mathrm{Ch}^{\mathrm{R}}$ & $T^{k}$ & & & $\mathrm{Ch}^{\mathrm{R}}$ & $T^{R}$ \\
\hline CB22 & $t_{48}$ & $1.7 \times 10^{8}$ & $1.2 \times 10^{5}$ & 250 & $t_{0}$ & $2 \times 10^{8}$ & $4 \times 10^{8}$ \\
\hline CB22 & $t_{20}$ & $7 \times 10^{7}$ & $2 \times 10^{5}$ & 50 & $t_{6}$ & $3 \times 10^{8}$ & $2 \cdot 6 \times 10^{8}$ \\
\hline CB22 & $t_{30}$ & $1 \times 10^{8}$ & $6 \times 10^{7}$ & 50 & $\exp$ & $3 \times 10^{8}$ & $2 \times 10^{8}$ \\
\hline $\mathrm{AB} 12$ & $t_{30}$ & $8 \times 10^{7}$ & $6 \times 10^{5}$ & 50 & $\exp$ & $4 \times 10^{8}$ & $5 \times 10^{8}$ \\
\hline $\mathrm{AB} 12$ & $t_{30}$ & $8 \times 10^{7}$ & $6 \times 10^{4}$ & 50 & exp & $7 \times 10^{8}$ & $1 \times 10^{9}$ \\
\hline $\mathrm{AB} 12$ & $t_{30}$ & $1 \times 10^{8}$ & $1.5 \times 10^{7}$ & 50 & exp & $6 \times 10^{8}$ & $4 \times 10^{8}$ \\
\hline
\end{tabular}

become heat-resistant. Therefore the phenotype of the strain should be "chloroform-resistant and DPA-dependent heat-resistant spores' $\left(\mathrm{Ch}^{\mathrm{R}}, \mathrm{Dpa}^{\mathrm{D}}-\mathrm{T}^{\mathrm{R}}\right)$, which will be abbreviated to DPA-less $\left(\mathrm{Dpa}^{-}\right)$. Control experiments showed that the presence of DPA during the heat treatment of $\mathrm{Dpa}^{-}$spores did not change their heat sensitivity. Sporulation of oligosporogenous strains is frequently temperature-sensitive, but this was not so with the Dpaphenotype of strain CB22: the frequency of $\mathrm{Ch}^{\mathrm{R}}$ and $\mathrm{T}^{\mathrm{R}}$ spores was the same in cultures grown at $30^{\circ} \mathrm{C}$ or at $45^{\circ} \mathrm{C}$.

\section{Genetic mapping of the dpa-I mutation}

Strain CB22 was obtained by $N$-methyl- $N^{\prime}$-nitro- $N$-nitrosoguanidine-induced mutagenesis in conditions where mutants were produced at high frequencies and multiple mutations could be frequent (Balassa, 1969). To demonstrate that the phenotype of CB22 spores is due to a single mutation it was transformed from CB22 into strain PM9 which sporulates normally. The frequency of Dpa- transformants ( $2 \%$ of the transformants for an auxotrophic marker) was consistent with the Dpa- phenotype arising from a single mutation, designated $d p a-1$. One of the transformants, $\mathrm{AB} 12$, was used in further studies of the $d p a-1$ mutation. Its phenotype was similar to $\mathrm{CB} 22$ with respect to the spore resistances and the DPA effect (Table 2). However, we found that AB12 was not motile and not transducible, and so another strain, AC28, was derived from it by further transformation. This latter strain was used for genetic mapping, by PBS1-mediated transduction, of the $d p a-1$ mutation.

The results of a cross between AC28 as donor and PM12 as recipient indicated linkage between $d p a-1$ and pyrAl (35\% cotransduction). Loose linkage was found between metC and $p y r A$ (less than $2 \%$ cotransduction), but no linkage was detected between metC and $d p a-1$. Thus the gene order metC-pyrA-dpa is suggested, with a distance $(100 \%$ cotransfer) of 65 units between pyr $A$ and $d p a$.

Generally the $d p a-1$ transformants and transductants had the same phenotype as CB22. Sometimes, however, intermediate phenotypes, sensitive to the addition of DPA but which sporulated even in its presence only at relatively low frequencies, were also found: these were not investigated further.

\section{Characterization of dpa-1 strains}

Development of heat resistance is one of the last events in the process of spore maturation. One would expect, therefore, that the early steps of spore formation would not be affected by the $d p a-1$ mutation. This seems to be the case with the synthesis of extracellular protease (Dod et al., 1978) since $d p a-1$ strains had normal protease activities. Wild-type spores are 


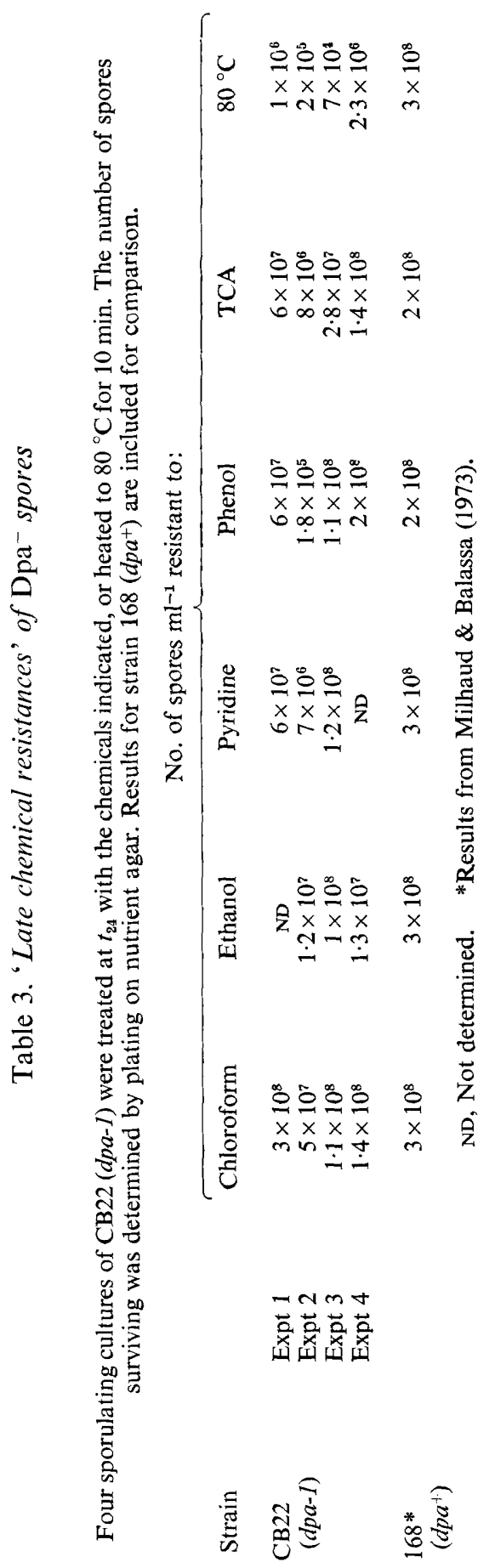


Table 4. Heat resistance of $\mathrm{Dpa}^{-}$spores

Sporulating cultures were heated as indicated.

\begin{tabular}{ccccc} 
& & \multicolumn{3}{c}{ No. of spores $\mathrm{ml}^{-1}$ surviving: } \\
Strain & $\begin{array}{c}\text { Sporulation } \\
\text { time }\end{array}$ & $\begin{array}{c}80^{\circ} \mathrm{C} \\
10 \mathrm{~min}\end{array}$ & $30{ }^{\circ} \mathrm{C}$ & $90{ }^{\circ} \mathrm{C}$ \\
CB22 $(d p a-l)$ & $t_{30}$ & $1 \cdot 5 \times 10^{8}$ & $6 \times 10^{4}$ & $10 \mathrm{~min}$ \\
CB22 $(d p a-l)$ & $t_{20}$ & $1 \times 10^{5}$ & $1 \cdot 7 \times 10^{2}$ & $7 \times 10^{3}$ \\
$\mathrm{AB} 12(d p a-l)$ & $t_{30}$ & $3 \times 10^{6}$ & $4 \times 10^{4}$ & 0 \\
$168\left(d p a^{+}\right)$ & $t_{20}$ & $4 \times 10^{8}$ & $4 \times 10^{8}$ & $4 \times 10^{4}$ \\
& & &
\end{tabular}

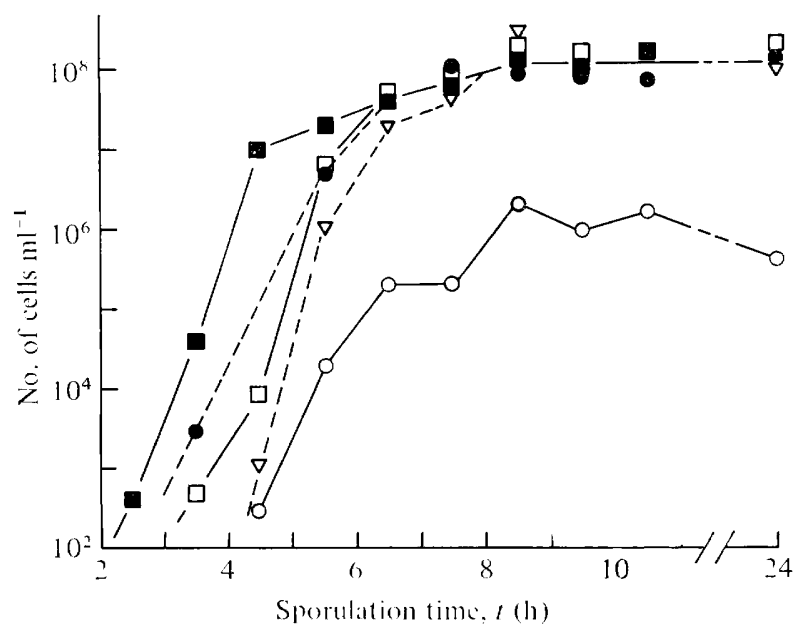

Fig. 1. Development of chemical resistances during sporulation of strain CB22. Samples of a sporulating culture were tested every hour for resistance to toluene $(\boldsymbol{\square})$, octanol $(\boldsymbol{O})$, chloroform $(\square)$, pyridine $(\nabla)$ and to $80^{\circ} \mathrm{C}$ for $10 \mathrm{~min}(\bigcirc)$. The number of cells surviving each treatment is indicated.

resistant to various chemicals, and these resistances appear sequentially during spore development (Milhaud \& Balassa, 1973). Mutants have been isolated whose spores are resistant to some chemical agents but not to others (Balassa et al., 1974). We therefore measured the chemical resistances of $\mathrm{Dpa}^{-}$spores to see if they were affected.

In the wild type, resistances to toluene, benzene, octanol, butanol and chloroform are the first to appear; Dpa- spores were completely resistant to these solvents. In contrast, resistances which normally appear after chloroform resistance, i.e. to ethanol, pyridine, phenol and TCA, were attained only with decreasing frequencies by Dpa-spores (Table 3). These frequencies, although varying from one experiment to another, were always higher than the frequency of $\mathrm{T}^{\mathrm{R}}$ spores. On the basis of the decreasing frequencies, the following order of resistances is tentatively proposed: chloroform-ethanol-pyridine-phenol, TCA$80^{\circ} \mathrm{C}$ for $10 \mathrm{~min}$. Wild-type spores were equally resistant to all these agents (Table 3 ).

Treatment for $10 \mathrm{~min}$ at $80{ }^{\circ} \mathrm{C}$ does not detect the last step in spore formation. Appearance of this resistance is followed by further slow maturation leading to resistance of the spores to higher temperatures and for longer periods (Milhaud \& Balassa, 1973). At $t_{20}$ wild-type spores survive for $60 \mathrm{~min}$ at $80^{\circ} \mathrm{C}$ or at $90^{\circ} \mathrm{C}$. The $\mathrm{T}^{\mathrm{R}}$ spores of $d p a-l$ strains were much less resistant (Table 4). Even in experiments where the frequency of $\mathrm{T}^{\mathrm{R}}$ spores (detected by heating at $80^{\circ} \mathrm{C}$ for $10 \mathrm{~min}$ ) was exceptionally high (Table 4, line 1), incubation for a longer period or at a higher temperature killed most of the spores, allowing one to distinguish $d p a-1$ from wild-type cultures. 


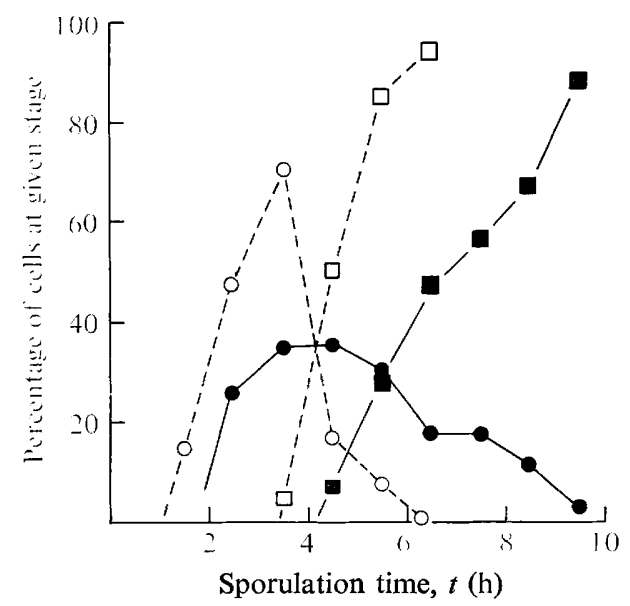

Fig. 2. Morphological development during sporulation of strain CB22 (dpa- $1 ;--)$ and strain 168 $\left(d p a^{+} ;---\right)$. The percentage of cells at morphological stage III $(O, O)$ and the percentage that had reached at least stage $V(\boldsymbol{\square}, \square)$ are indicated.

\section{Kinetics of development of $\mathrm{Dpa}^{-}$spores}

The low frequency of heat-resistant spores could be due to delayed or slow sporulation of $d p a-1$ strains in the absence of DPA. Mutants in which the development of chemical resistances is slowed down ('decadent' mutants) have been described (Balassa et al., 1974, 1979). It was therefore of interest to follow in detail the kinetics of spore formation and the appearance of various chemical resistances in a $d p a-1$ strain. The original CB22 strain was used. (This strain appears to be phenotypically identical to AB12 and preliminary experiments with the latter gave similar results.) Compared with the development of wildtype spores (Milhaud \& Balassa, 1973), all the chemical resistances developed somewhat later in $d p a-1$ cultures (Fig. 1). The development of heat resistance was particularly slow. When this was followed in sporulating cultures for $4 \mathrm{~d}$, the number of spores resistant to chloroform and to heat $\left(80^{\circ} \mathrm{C}\right.$ for $\left.10 \mathrm{~min}\right)$ did not rise after $t_{24}$ and the spores appeared to be stable. The number of spores surviving a more exacting heat treatment $\left(90^{\circ} \mathrm{C}\right.$ for 10 min) increased slowly but continuously from 40 spores $\mathrm{ml}^{-1}$ after $1 \mathrm{~d}$ sporulation to over $10^{5}$ spores $\mathrm{ml}^{-1}$ after $4 \mathrm{~d}$. These results suggest that a slow, continuous maturation takes place in $d p a-I$ spores; the mutation could be leaky.

The development of a Dpa- culture was also followed by electron microscopy and compared with results obtained with the wild-type strain 168 (Sousa et al., 1978). Samples of sporulating cultures were taken every hour and the number of cells at the different morphological stages was counted in thin sections as described by Sousa et al. (1978). In each sample 200 to 500 cells were counted. Since cells blocked at stages II and IV were relatively rare, only the frequencies of cells blocked at stages III and V or VI are shown in Fig. 2. There was only a slight delay in the appearance of stage III cells in the $\mathrm{Dpa}^{-}$culture, and in both cultures the frequencies of stage III cells were highest at around $t_{3 \cdot 5}$. In the CB22 culture, however, there was a significant 'trail' of cells which reached stage III much later (or which remained longer at stage III). Stages V and VI were difficult to distinguish in $\mathrm{Dpa}^{-}$cells, so late spore development was followed in both cultures by measuring the frequency of cells which had reached at least stage V (stage V plus stage VI cells plus free spores). The appearance of stage $\mathrm{V}$ cells was clearly delayed in the Dpa- culture (Fig. 2). These observations are consistent with those on the development of chemical resistances. Sporulation of $\mathrm{Dpa}^{-}$strains appeared to be delayed and this delay was much more pronounced for later stages than for earlier stages. Such delays have been observed in more detail with 'decadent' mutants (Balassa et al., 1979). 
Table 5. Incorporation of external DPA into $\mathrm{Dpa}^{-}$spores

DPA was added to nutrient broth cultures before $t_{0}$. Spores were collected at $t_{20}$.

$\begin{array}{ccc}\text { DPA added } & \text { DPA in spores } \\ \left(\mu \mathrm{g} \mathrm{ml}^{-1}\right) & \left.[\mu \mathrm{g} \mathrm{(ml} \mathrm{culture})^{-1}\right]\end{array}$

CB22 (dpa-1)

$\mathrm{AB} 12($ dpa-l)

PM9 $\left(d p a^{+}\right)$

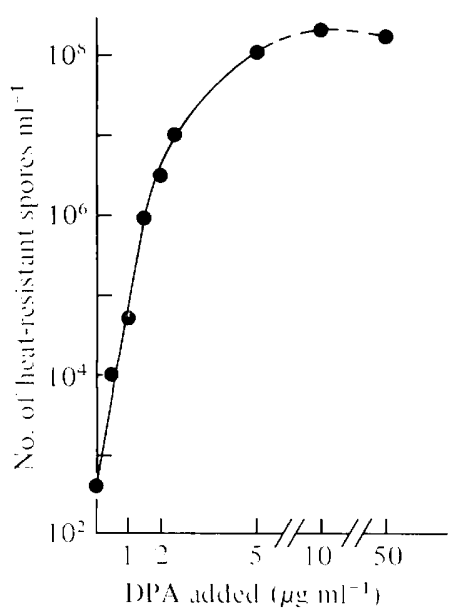

Fig. 3

$\begin{array}{rr}0 & 3 \\ 50 & 18 \\ 0 & 3 \\ 50 & 31 \\ 0 & 31 \\ 50 & 33\end{array}$

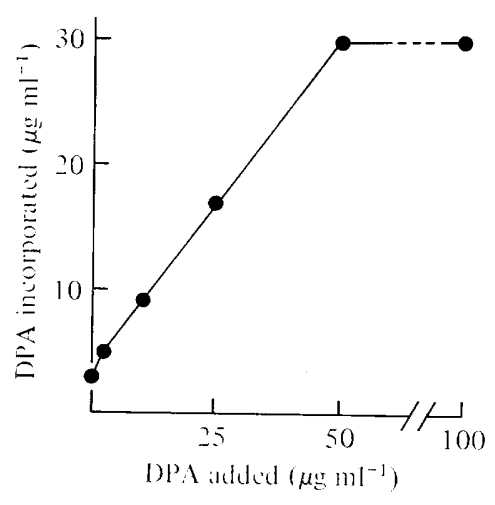

Fig. 4

Fig. 3. Dependence of the heat resistance of $\mathrm{Dpa}^{-}$spores on the concentration of added DPA. Various concentrations of DPA were added to CB22 cultures at $t_{2}$. The heat resistance of the spores was tested at $t_{20}$. The number of spores resistant to chloroform was the same in all the cultures.

Fig. 4. Concentration dependence of DPA incorporation. Various concentrations of DPA were added to CB22 cultures at $t_{1}$. The incorporation of DPA was measured in spores collected at $t_{20}$.

\section{Incorporation of DPA into dpa-1 spores}

The inability of $d p a-1$ spores to attain heat resistance and their response to added DPA suggested that $d p a$ strains were unable to synthesize (or accumulate) DPA. This was indeed the case (Table 5): $d p a-1$ spores contained 6 to 10 times less DPA than wild-type spores. The small residual amounts of DPA could explain the presence of rare $\mathrm{T}^{\mathrm{R}}$ spores in $d p a-1$ cultures. This would suggest a heterogeneity in the distribution of residual DPA among dpa-1 spores. [The colorimetric assay for DPA is known to be specific (Janssen et al., 1958). No further attempt was made to identify chemically the residual amounts.] Addition of DPA to the cultures was followed by its incorporation into the spores. Spores of $d p a-1$ cultures formed in the presence of external DPA contained normal or almost normal amounts (60 to $100 \%$ ) of DPA. The DPA content of wild-type spores, however, was not influenced by external DPA (Table 5).

The effect of added DPA on the development of heat resistance in dpa-1 spores was concentration-dependent. For low external concentrations of DPA (from 0 to $2.5 \mu \mathrm{g} \mathrm{ml}^{-1}$ ) there was a linear correlation between the logarithm of the $\mathrm{T}^{\mathrm{R}}$ spore count and the concentration of DPA (Fig. 3). All the spores became heat-resistant in the presence of $5 \mu \mathrm{g}$ DPA $\mathrm{ml}^{-1}$. When incorporation of DPA into the spores was followed chemically, a linear correlation was found betwen the concentration of DPA added and the amount of DPA 


\section{Table 6. Incorporation of DPA, added at different times during sporulation, into $\mathrm{Dpa}^{-}$spores}

DPA $\left(250 \mu \mathrm{g} \mathrm{ml}^{-1}\right)$ was added to a CB22 (dpa-1) culture at the times indicated. Incorporation of DPA and heat resistance $\left(80^{\circ} \mathrm{C}, 10 \mathrm{~min}\right)$ were measured at $t_{20}\left(\right.$ or, when DPA was added at $t_{20}$, at $\left.t_{48}\right)$.

\begin{tabular}{|c|c|c|c|c|c|c|}
\hline \multirow[t]{2}{*}{$40 \%$} & \multirow{2}{*}{$\begin{array}{c}\text { No DPA } \\
\text { added }\end{array}$} & \multicolumn{5}{|c|}{ DPA added at: } \\
\hline & & $t_{0}$ & $t_{2}$ & $t_{4}$ & $t_{6}$ & $t_{20}$ \\
\hline $\begin{array}{l}\text { DPA incorporated } \\
\left(\mu \mathrm{g} \mathrm{ml}^{-1}\right)\end{array}$ & 6 & 27 & 32 & 25 & 26 & 19 \\
\hline $\begin{array}{l}\text { No. of heat-resistant } \\
\text { spores } \mathrm{ml}^{-1}\end{array}$ & $2.0 \times 10^{4}$ & $2 \cdot 2 \times 10^{8}$ & $1.7 \times 10^{8}$ & $1.9 \times 10^{8}$ & $2.4 \times 10^{8}$ & $1.2 \times 10^{8}$ \\
\hline
\end{tabular}

\section{Table 7. Sporulation of strain CB22 in mixed cultures}

Cultures of CB22 (dpa-l) and of 'wild-type' strain $168\left(d p a^{+}\right)$were mixed during exponential growth in the proportions indicated. After plating viable and heat-resistant cells at $t_{20}$, colonies of CB22 were counted on the basis of their white colour (distinct from the brown colonies of 168). Over $50 \%$ of the strain 168 cells formed heat-resistant spores in the mixed cultures.

\begin{tabular}{|c|c|c|c|c|c|c|}
\hline & & Prop & ion of $\mathrm{CE}$ & in the init & cultures & \\
\hline & $1 \cdot 0$ & 0.9 & $0 \cdot 8$ & 0.5 & 0.2 & $0 \cdot 1$ \\
\hline $\begin{array}{l}\text { Percentage of viable CB22 } \\
\text { cells at } t_{20}\end{array}$ & 100 & 86 & 78 & 57 & 17 & 8 \\
\hline $\begin{array}{l}\text { No. of viable CB22 } \\
\text { cells } \mathrm{ml}^{-1} \text { at } t_{20}\end{array}$ & - & $1 \times 10^{9}$ & $1 \cdot 2 \times 10^{9}$ & $6 \times 10^{8}$ & $1.7 \times 10^{8}$ & $1 \times 10^{8}$ \\
\hline $\begin{array}{l}\text { No. of heat-resistant } \\
\text { CB22 spores } \mathrm{ml}^{-1} \text { at } t_{20}\end{array}$ & $2 \times 10^{4}$ & $3 \times 10^{7}$ & $1 \cdot 1 \times 10^{7}$ & $6.5 \times 10^{7}$ & $1 \cdot 3 \times 10^{8}$ & $1.2 \times 10^{8}$ \\
\hline
\end{tabular}

incorporated (Fig. 4). Saturating concentrations were much higher (about $50 \mu \mathrm{g} \mathrm{m}^{-1}$ ) than for the development of heat resistance (Fig. 3). Thus the heat resistance of spores is not a linear function of the amount of DPA incorporated.

In wild-type cells DPA synthesis starts at about stage III and all the spores become heat-resistant before $t_{7}$. It was possible therefore, that there might be a limited period for the incorporation of DPA into $d p a-1$ forespores. This is not so, however, since addition of DPA at any time between $t_{0}$ and $t_{6}$ allowed all the spores to become heat-resistant and to incorporate normal amounts of DPA (Table 6). Even when DPA was added to sporulating cultures at $t_{20}$, long after the completion of spore formation, all the spores became heat resistant and their DPA contents reached about $60 \%$ of that of the wild type. This observation allowed us to follow incorporation of DPA indirectly by measuring the number of $\mathrm{T}^{\mathrm{R}}$ spores after late addition of DPA. As soon as DPA was added to $t_{20}$ cultures (containing $\mathrm{Ch}^{\mathrm{R}}$ spores which were presumably mature in all respects but for their DPA content), the number of $T^{R}$ spores started to increase. On the basis of the earlier results (Fig. 3), this increase corresponded to the incorporation of small amounts (less than $5 \mu \mathrm{g} \mathrm{ml}^{-1}$ ) of DPA. Incorporation of DPA was very slow, and the maximum number of $T^{R}$ spores was not reached until 5 to $10 \mathrm{~h}$ after its addition. It is not clear if integrity of the sporangium is required for DPA incorporation since in $d p a-1$ cultures the majority of the forespores remained enclosed in the sporangium even at $t_{20}$. One might expect DPA incorporation to be faster if it is added at 'physiological times' (i.e. $t_{3}$ to $t_{6}$ ); preliminary observations suggest that this is not so.

\section{Conditions for DPA incorporation}

Incorporation of DPA was temperature-dependent since no $T^{R}$ spores developed when the culture was kept, after addition of DPA, at $4{ }^{\circ} \mathrm{C}$. It was completely inhibited by $\mathrm{KCN}$ and by chloroform but not by chloramphenicol (streptomycin had a weak effect). Since 
Table 8. Effect of DPA on the 'late chemical resistances'

DPA $\left(50 \mu \mathrm{g} \mathrm{ml}^{-1}\right)$ was added to strain AB12 (dpa-I) during exponential growth. Spore resistances were tested at $t_{30}$.

No. of spores $\mathrm{ml}^{-1}$ resistant to:

$\begin{array}{lccccc} & \text { Chloroform } & \text { Pyridine } & \text { Phenol } & \text { TCA } & 80^{\circ} \mathrm{C} \\ \text { DPA absent } & 1 \times 10^{8} & 5 \times 10^{7} & 2 \times 10^{7} & 6 \times 10^{5} & 1.5 \times 10^{7} \\ \text { DPA present } & 6 \times 10^{8} & 5 \times 10^{8} & 3 \times 10^{8} & 3 \times 10^{8} & 4 \times 10^{8}\end{array}$

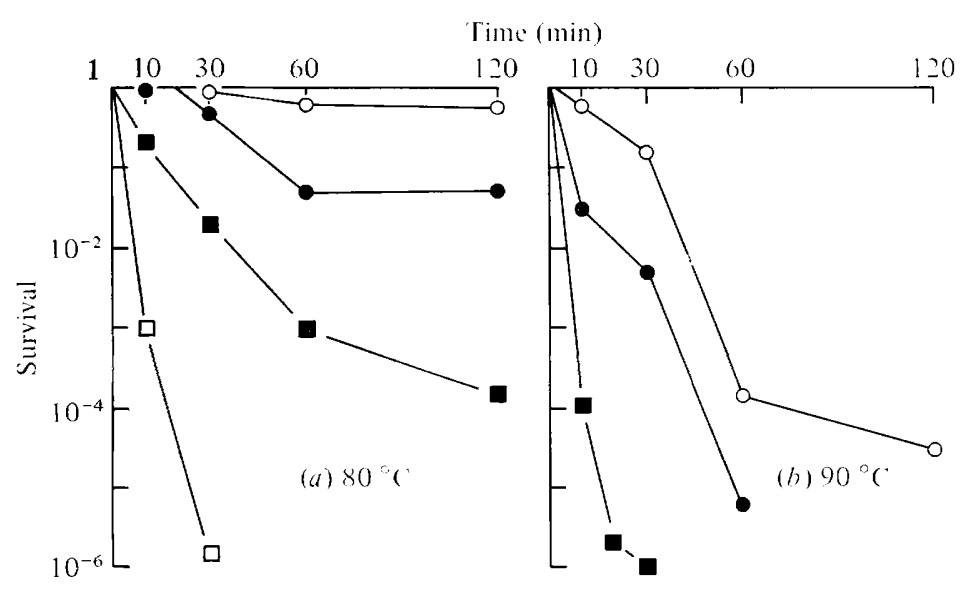

Fig. 5. Heat resistance of spores obtained in the presence of limiting concentrations of DPA. At $t_{1}$ DPA was added to CB22 cultures at $\left(\mu \mathrm{g} \mathrm{ml}^{-1}\right): 0,25 ; 0,10 ; \mathbf{E}, 2.5 ; \square, 0$. Samples were taken at $t_{20}$ and tested directly for heat resistance at $80^{\circ} \mathrm{C}(a)$ and $90^{\circ} \mathrm{C}(\mathrm{b})$. Survival is expressed relative to the number of cells resistant to chloroform.

chloramphenicol inhibits protein synthesis in the forespores until spore maturation (see Balassa, 1966), these results suggest that DPA incorporation is an active process requiring energy but not protein synthesis. DPA was incorporated not only in nutrient broth cultures but also into cells resuspended in Tris buffer. The presence of bivalent ions $\left(\mathrm{Ca}^{2+}, \mathrm{Fe}^{2+}\right.$ or $\mathrm{Mn}^{2+}$ ) was apparently not required for DPA incorporation.

Sporulating cultures excrete DPA into the medium (Sebald, 1968). A syntrophy-like phenomenon, i.e. sporulation of $d p a-1$ cells in mixed cultures with $d p a^{+}$cells, might therefore be expected. This was indeed the case: CB22 cells developed heat-resistant spores when grown together with strain 168 cells (Table 7). In cultures containing only $10 \%$ wild-type cells, the frequency of $d p a-1 \mathrm{~T}^{\mathrm{R}}$ spores had increased from $2 \times 10^{-5}$ to $3 \times 10^{-2}$. This frequency increased with the proportion of $d p a^{+}$cells and all the CB22 spores developed $\mathrm{T}^{\mathrm{R}}$ spores in cultures where the strain 168 cells were predominant. From these results, the amount of DPA excreted by strain 168 cells during sporulation is estimated to be about 5 to $10 \mu \mathrm{g} \mathrm{ml}^{-1}$, i.e. one-sixth to one-third of the DPA contained in the spores.

\section{Properties of dpa-1 spores obtained in the presence of DPA}

Spores obtained from $d p a-1$ strains in the presence of excess DPA appeared to be phenocopies of wild-type spores. To ascertain whether they were truly identical or still retained some properties of $d p a-l$ spores, their heat resistance was measured in the presence of DPA. Spores of CB22 or AB12 obtained with excess DPA survived as well as wild-type spores at $80{ }^{\circ} \mathrm{C}$ for up to $120 \mathrm{~min}$ or at $90^{\circ} \mathrm{C}$ for up to $30 \mathrm{~min}$. There was therefore no indication that these spores were less heat resistant. Addition of DPA during sporulation also restored the 'late chemical resistances' (to pyridine, phenol and TCA) of $d p a-1$ spores (Table 8). 

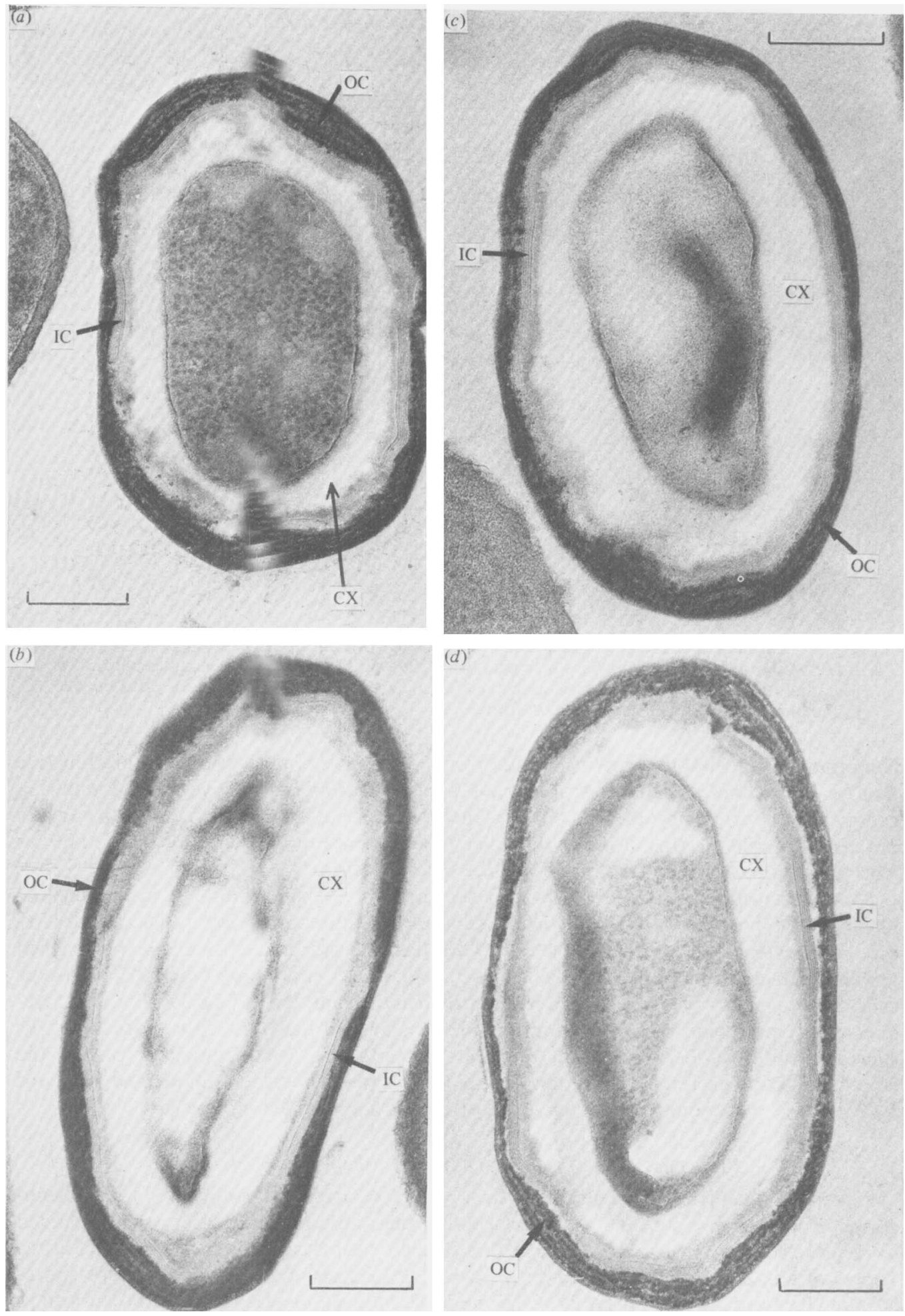


\section{Table 9. Morphology of $\mathrm{Dpa}^{-}$spores}

DPA was added, when indicated, to $100 \mu \mathrm{g} \mathrm{ml}^{-1}$. In each sample 60 to 200 spores were examined for the fine structure of the spore core, i.e. visibility of the ribosomes and of the cytoplasmic membrane.

\begin{tabular}{ccccc} 
& & \multicolumn{3}{c}{$\begin{array}{c}\text { Percentage of spores with the core } \\
\text { fine structure: }\end{array}$} \\
\cline { 3 - 5 } Strain & DPA added & Visible & Intermediate & Invisible \\
AB12 $(d p a-1)$ & None & 92 & 8 & 0 \\
AB12 $(d p a-1)$ & $t_{1 \cdot 5}$ & 31 & 50 & 19 \\
AB12 $(d p a-1)$ & $t_{7 \cdot 5}$ & 19 & 60 & 22 \\
PM9 $\left(d p a^{+}\right)$ & None & 0 & 0 & 100
\end{tabular}

One should not conclude from these observations that resistance of the spores is an allor-none phenomenon. Intermediate resistances could be obtained by adding limiting concentrations of DPA. The heat resistance of spores obtained without DPA and in the presence of low concentrations of DPA was measured at $80^{\circ} \mathrm{C}$ and at $90^{\circ} \mathrm{C}$ (Fig. 5). The rare $d p a-1$ spores resistant to $80^{\circ} \mathrm{C}$ for $10 \mathrm{~min}$ were still sensitive to longer treatment or to incubation at $90{ }^{\circ} \mathrm{C}$. Spores obtained in the presence of $2 \cdot 5,10$ or $25 \mu \mathrm{g} \mathrm{DPA} \mathrm{ml}{ }^{-1}$ showed intermediate resistances. Both the initial rate of decay and the resistant fraction increased in spores obtained with increasing concentrations of DPA. It seems that the curves of Fig. 5 derive from the two phenomena - increasing resistance of the majority of spores and heterogeneity of the population with the more resistant spores becoming more frequent.

\section{Morphology of $\mathrm{Dpa}^{-}$spores}

Earlier electron microscopic observations (Balassa \& Yamamoto, 1970) failed to detect any significant morphological difference between normal and CB22 spores; in these experiments thin sections of spores were post-stained with uranyl acetate followed by lead citrate. In the present work the fine structure of $\mathrm{Dpa}^{-}$spores was examined in thin sections that had not been post-stained. Spores of the isogenic strains AB12 and PM9 were compared. No difference was found in the spore envelopes, but the appearance of the spore core was completely different in the two preparations. Dpa- spores of AB12 exhibited a well-defined cytoplasmic membrane and evenly distributed ribosomes in the cytoplasm (Fig. 6a). Neither of these structures was seen in wild-type spores (Fig. 6b) which had the typical structureless, ill-defined apppearance of mature spores. When spores of the $d p a-1$ strain were obtained in the presence of excess DPA, the appearance of the spore core was changed. The spore population was heterogeneous: in some spores none of the spore core structures were visible (Fig. 6c), some looked like the $\mathrm{Dpa}^{-}$spores and some had an intermediate appearance, with the cytoplasmic membrane and the ribosomes still more or less visible but blurred (Fig. $6 d$; Table 9). This heterogeneity is probably related to the heterogeneity of the spores obtained in the presence of DPA with respect to heat resistance.

Fig. 6. Thin sections of spores sampled at $t_{20}$ : CX, cortex; IC, inner coat; OC, outer coat. All bar markers represent $0.25 \mu \mathrm{m}$.

(a) Spore of AB12 (dpa-l) produced in the absence of DPA. The ribosomes and the cytoplasmic membrane are clearly visible.

(b) Spore of PM9 $\left(d p a^{+}\right)$produced in the absence of DPA. The spore core has the typical structureless appearance of mature spores.

(c) Spore of $\mathrm{AB} 12(d p a-l)$ produced in the presence of DPA $\left(50 \mu \mathrm{g} \mathrm{ml}^{-1}\right.$, added at $\left.t_{1 \cdot 5}\right)$. The spore core has a structureless appearance as in $(b)$.

(d) Spore of AB12 (dpa-l) produced in the presence of DPA (as in $c$ ). The ribosomes of the spore are visible but not so clearly as in $(a)$. 


\section{DISCUSSION}

Strain CB22 carries a mutation that prevents the development of heat-resistant spores unless external DPA is added to the cultures. Sporulating CB22 cells are unable to synthesize normal amounts of DPA. Although many sporulation mutations prevent synthesis or accumulation of DPA (see below), few of them exhibit the 'DPA-dependent conditional heat resistance' phenotype. Sebald (1968) has described a Clostridium histolyticum mutant with similar properties: the mutant spores failed to become heat-resistant in the absence of DPA. Addition of DPA resulted in the slow development of heat resistance. This effect was

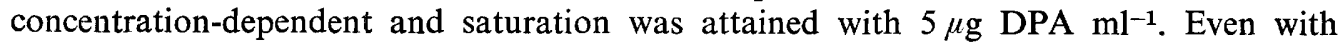
excess DPA, however, only a fraction of the population attained resistance. Fukuda \& Gilvarg (1968) isolated a Bacillus megaterium mutant lacking the condensing enzyme involved in the synthesis of dihydrodipicolinic acid. This mutant, grown in the presence of lysine and diaminopimelic acid, required DPA for the development of heat-resistant spores. Spores obtained without DPA were heat-sensitive, devoid of $\mathrm{Ca}^{2+}$ and exhibited a lower buoyant density. Bacillus cereus mutants of similar phenotype have also been briefly mentioned (Wise et al., 1967), but genetic studies were not possible with these mutants. To our knowledge, $B$. subtilis mutants of this type have not previously been found.

The dpa-1 mutation described here seems to concern directly the synthesis of DPA. The strain grows normally in synthetic media and does not require lysine and/or diaminopimelic acid. Transport or retention of DPA are not likely to be affected since external DPA is incorporated and concentrated. Thus it is likely that the last step of DPA synthesis is affected and that the mutation could be in the structural gene of DPA-synthetase. However, the possibility of a regulatory mutation is not excluded. Dpa ${ }^{-}$cells form heat-resistant spores with low frequency and contain low amounts of DPA. These properties, and the slow increase in spores resistant to $90^{\circ} \mathrm{C}$, suggest either that the mutation is leaky or that DPA is slowly formed by spontaneous oxidation, in a non-enzymic manner.

The $\mathrm{Dpa}^{-}$phenotype is due to a single mutation located in a new locus, dpa. The locus is linked to pyr $A$. This is one of the rare instances where the primary biochemical defect of a sporulation locus is known. No precise mapping of $d p a$ with respect to the neighbouring sporulation genes was done. Among the loci situated in the same region, a stage III locus, SpoIIIE, seems to map close to dpa. Two late mutations are also in the same region (SpoVD and SpoVE; Piggot \& Coote, 1966). The phenotype of these mutants appears to be sufficiently different from the $\mathrm{Dpa}^{-}$phenotype to be sure that they belong to different loci. There is no indication at present of an operon-like organization involving $d p a$.

Synthesis of DPA is under the genetic control of sporulation genes related by one-directional pleiotropic interactions (Balassa, 1969, 1971). As a general rule, no early sporulation mutants are able to produce DPA. The phenotype of the $\mathrm{Dpa}^{-}$strains, with spores which are heat-sensitive but apparently mature in every other respect, suggests that DPA synthesis could be the last step (or one of the last steps) of the pleiotropic sequence. The actual situation is more complex: among the late mutants, blocked at stage IV and V and affected in the development of the cortex and/or the spore coats, some fail to synthesize DPA, others are unable to accumulate or to retain DPA and excrete it into the medium, while a few contain normal amounts of DPA (Sebald, 1968; Fitz-James \& Young, 1969; Coote, 1972). It seems that, although prior functioning of the majority of sporulation genes is required for DPA synthesis, the end of the pleiotropic sequence is branched. However, one could still consider that the $d p a-1$ mutation blocks sporulation later than any other known sporulation mutation.

The principal characteristics of $\mathrm{Dpa}^{-}$spores are their heat sensitivity and the lack of DPA. Although no comparison of $\mathrm{Dpa}^{-}$spores with vegetative cells was made for the rate of heat inactivation at lower temperatures, from extrapolation of the results of Fig. 5 it seems likely that $\mathrm{Dpa}^{-}$spores are more resistant than vegetative cells, due either to the low 
amount of DPA present or to other spore structures. Preliminary experiments (with $\mathrm{Dr}$ $\mathrm{H}$. Ohlenbusch) show that $\mathrm{Dpa}^{-}$spores are also lighter and contain less calcium than wild-type spores. However, they attain normal resistance to treatment with organic solvents, including octanol and chloroform. This confirms previous suggestions (e.g. Ryter, 1965; Milhaud \& Balassa, 1973; Sousa et al., 1978) that resistance to these solvents is due to the spore envelopes (essentially the spore coats). 'Late chemical resistances', e.g. to ethanol, pyridine, phenol and TCA, are incomplete or absent from the Dpa- spores. Observations with this mutant confirm the order of resistances deduced from kinetic studies with the wild type (Milhaud \& Balassa, 1973). They suggest that the latter resistances are, at least in part, due to a mechanism common to that of heat resistance and which involves DPA. [As suggested previously (Milhaud \& Balassa, 1973), the action of ethanol and pyridine could involve dehydration of the spore.] Addition of DPA leads to the recovery of the "late chemical resistances.'

Incorporation of external DPA does not apparently require protein synthesis, but it appears to be an energy-dependent active process. This is not surprising since DPA concentration in the spore can attain $15 \%$ of the dry weight (Gould \& Dring, 1974) and accumulation against such a high concentration gradient is likely to require energy. Incorporation into the forespore must be preceded by the crossing of two or three membranes: the cytoplasmic membrane of the mother cell, the forespore membrane and, if its integrity is preserved at the time of DPA incorporation, the outer spore membrane which has opposite polarity. This might explain the slow accumulation of DPA. The role of the sporangium in the uptake of DPA was not investigated. It should be noted that in normally sporulating cells DPA synthesis apparently occurs in the sporangium and not in the forespore (Andreoli et al., 1975).

The fact that DPA can be incorporated into spores in the absence of protein synthesis, and that spores formed in this way are stable and maintain their resistance, suggests that the structure(s) and/or metabolites necessary for the retention of DPA are formed during sporulation even if DPA is not present. High amounts of calcium do not seem to be required.

Heat resistance is not an all-or-none phenomenon. Although excess DPA seems to permit complete recovery of heat resistance, non-saturating concentrations give rise to spores with intermediate heat resistance. The relationship between DPA content and heat resistance is not linear, which is what one would expect if heat resistance is due to a multimeric DPA-containing structure. This aspect requires further investigation, in particular by measuring the DPA content and heat resistance of homogeneous spore fractions (e.g. purified by density gradient centrifugation). Dpa- ${ }^{-}$spores seem to constitute a particularly useful model system for studying the accumulation and retention of DPA and of calcium. Spores containing varying amounts of DPA (and perhaps of calcium) can be obtained. A very sensitive bioassay can also be developed since quantities as low as $0.5 \mu \mathrm{g} \mathrm{DPA} \mathrm{ml}^{-1}$ can easily be detected by measuring the number of $\mathrm{T}^{\mathrm{R}}$ spores.

The properties of $\mathrm{Dpa}^{-}$spores provide additional information for the discussion of the possible role of DPA and of the mechanism of heat resistance in bacterial spores. The status of this problem was reviewed by Gould \& Dring (1974). Observations with Dpaspores of $\mathrm{Cl}$. histolyticum and $\mathrm{B}$. megaterium (see above) provided evidence for the direct involvement of DPA in heat resistance. On the other hand, several mutants lacking DPA but producing heat-resistant spores have been briefly reported (Hanson et al., 1972; Zytkovicz \& Halvorson, 1972). There is apparently a contradiction between these results and those obtained with other mutants including the $d p a-1$ strains. In the present study the observed correlation between the amounts of DPA incorporated and the heat resistance of the spores directly implicates DPA in the heat resistance of the spores. The properties of the abnormal Dpa- $\mathrm{T}^{\mathrm{R}}$ mutants mentioned above might be explained by: (i) an undetected technical artefact; (ii) the presence of a factor interfering with the DPA assay; (iii) 
accumulation in the mutant of a structural analogue of DPA (e.g. over-production of sulpholactic acid); (iv) a different mechanism of heat resistance in these strains.

DPA is localized in the spore core (Leanz \& Gilvarg, 1972). If, as seems likely, this is also true for external DPA incorporated in the spore, our results suggest that heat resistance is directly due to a biophysical change which occurs in the spore cytoplasm, and depends on the presence of high amounts of DPA. If this is so, the spore cortex and the spore coats are not directly involved in heat resistance, although they might play a role in the transport, accumulation or retention of DPA. Our observations are difficult to reconcile with the expanded cortex theory (Gould \& Dring, 1975). The preliminary observation that DPA incorporation can take place and confer heat resistance in the absence of calcium needs further confirmation. Electron microscopy confirmed that the spore population obtained in the presence of DPA is heterogeneous. It also suggests that the typical unstructured appearance of mature spores is directly due to the presence of DPA and not to a permeability barrier of the spores. Silva (unpublished) has observed, by measuring the speed of gelification of albumin and by ultrastructural studies of vegetative Bacillus cells, that DPA competes with $\mathrm{OsO}_{4}$ fixation. This finding may well explain the appearance of the DPAcontaining mature spore core.

We thank Drs B. Dod and H. Ohlenbusch for participation in preliminary experiments. This work was supported by grants from the Fondation pour la Recherche Médicale Française and from the Scientific Affairs Division of NATO.

\section{REFERENCES}

Andreoli, A. J., Saranto, J., Baecker, P. A., Suehiro, S., Escamilla, E. \& Steiner, A. (1975). Biochemical properties of forespores isolated from Bacillus cereus. In Spores VI, pp. 418-424. Edited by P. Gerhardt, R. N. Costilow \& H. L. Sadoff. Washington: American Society for Microbiology.

Balassa, G. (1966). Synthèse et fonction des ARN messagers au cours de la sporulation de Bacillus subtilis. Annales de l'Institut Pasteur 110, 175-191.

Balassa, G. (1969). Biochemical genetics of bacterial sporulation. I. Unidirectional pleiotropic interactions among genes controlling sporulation in Bacillus subtilis. Molecular and General Genetics 104, 73-103.

Balassa, G. (1971). The genetic control of spore formation in bacilli. Current Topics in Microbiology and Immunology 56, 99-192.

Balassa, G. \& Yamamoto, T. (1970). A Bacillus subtilis mutant with heat-sensitive but chloroformresistant spores. Microbios 5, 73-76.

Balassa, G., Dod, B., Milhaud, P., Serre, A., Silva, M. T. \& Sousa, J. (1974). The genetic control of late sporulation events in mutants of Bacillus subtilis: preliminary results. In Spore Research 1973, pp. 73-86. Edited by A. N. Barker, G. W. Gould \& J. Wolf. London: Academic Press.

Balassa, G., Milhaud, P., Sousa, J. C. F. \& SILVA, M. T. (1979). Decadent sporulation mutants of Bacillus subtiits. Journal of General Microbiology 110, 381-392.

CоOтE, J. G. (1972). Sporulation in Bacillus subtilis: genetic analysis of oligosporogenous mutants. Journal of General Microbiology 71, 1-15.

Dod, B., Balassa, G., Raulet, E. \& Jeannoda, V. (1978). Spore control (Sco) mutations in Bacillus subtilis. II. Sporulation and the production of extracellular proteases and amylase by $S c o$ mutants. Molecular and General Genetics 163, 45-56.

Fitz-JAMES, P. C. \& Young, E. (1969). Morphology of sporulation. In The Bacterial Spore, pp. 39-72. Edited by G. W. Gould \& A. Hurst. London: Academic Press.

Fukuda, A. \& GilvarG, C. (1968). The relationship of dipicolinate and lysine biosynthesis in Bacillus megaterium. Journal of Biological Chemistry 243, 3871-3876.

Gould, G. W. \& Dring, G. J. (1974). Mechanisms of spore heat resistance. Advances in Microbial Physiology 11, 137-164.

Gould, G. W. \& Dring, G. J. (1975). Role of an expanded cortex in resistance of bacterial endospores. In Spores VI, pp. 541-546. Edited by P. Gerhardt, R. N. Costilow \& H. L. Sadoff. Washington: American Society for Microbiology. Hanson, R. S., Curry, M. V., Garner, J. V. \& Halvorson, H. O. (1972). Mutants of Bacillus cereus strain $\mathrm{T}$ that produce thermoresistant spores lacking dipicolinate and have low levels of calcium. Canadian Journal of Microbiology 185, 1139-1143.

Janssen, F. W., Lund, A. J. \& Anderson, L. E. (1958). Colorimetric assay for dipicolinic acid in bacterial spores. Science 127, 26-27.

Leanz, G. F. \& Gilvarg, C. (1972). Localization of bacterial spore components by beta-attenuation analysis. In Spores $V$, pp. 45-48. Edited by H. O. Halvorson, R. Hanson \& L. L. Campbell. Washington: American Society for Microbiology. Milhaud, P. \& Balassa, G. (1973). Biochemical genetics of bacterial sporulation. IV. Sequential 
development of resistances to chemical and physical agents during sporulation of Bacillus subtilis. Molecular and General Genetics 125, 241-250.

Milhaud, P., Balassa, G. \& Zucca, J. (1978). Spore control $(S c o)$ mutations in Bacillus subtilis I. Selection and genetic mapping of Sco mutants. Molecular and General Genetics 163, 35-44.

Piggot, P. J. \& Coote, J. G. (1976). Genetic aspects of bacterial endospore formation. Bacteriological Reviews 40, 908-962.

Ryter, A. (1965). Étude morphologique de la sporulation de Bacillus subtilis. Annales de l' Institut Pasteur 108, 40-60.

Schaeffer, P., Ionesco, H., Ryter, A. \& Balassa, G. (1965). La sporulation de Bacillus subtilis: étude génétique et physiologique. Colloques internationaux du Centre national de la recherche scientifique 124, 553-563.

Sebald, M. (1968). Sur un mutant asporogène de Clostridium histolyticum incapable de synthétiser l'acide dipicolinique. Annales de l'Institut Pasteur 114, 265-276.

Sousa, J. C. F., Silva, M. T. \& Balassa, G. (1974). Biochemical genetics of bacterial sporulation. V. Fine structure analysis of two sporulation mutants of Bacillus subtilis derepressed for late functions. Molecular and General Genetics 128, 261-272.

Sousa, J. C. F., Silva, M. T. \& Balassa, G. (1978). Spore control ( $\mathrm{Sco}$ ) mutations in Bacillus subtilis. $\mathrm{V}$. Electron microscope study of delayed morphogenesis. Molecular and General Genetics 163, 285-291.

Wise, J., Swanson, A. \& Halvorson, H. O. (1967). Dipicolinic acid-less mutants of Bacillus cereus. Journal of Bacteriology 94, 2075-2076.

Zytkovicz, T. H. \& Halvorson, H. O. (1972). Some characteristics of dipicolinic acid-less mutant spores of Bacillus cereus, B. megaterium and $B$. subtilis. In Spores $V$, pp. 49-52. Edited by H. O. Halvorson, R. Hanson \& L. L. Campbell. Washington: American Society for Microbiology. 